\title{
A Review of Commercial Energy Harvesters for Autonomous Sensors
}

\author{
M. T. Penella, M. Gasulla. \\ Instrumentation, Sensors and Interfaces Group \\ Castelldefels School of Technology, Dept. Electronic Engineering, Technical University of Catalonia \\ Av. Canal Olímpic s/n 08860, Castelldefels, Spain, mpenella@eel.upc.edu Phone: +34934137089
}

\begin{abstract}
Current commercial autonomous sensors are mainly powered by primary batteries. Batteries need to be replaced and hence can become the largest and most expensive part of the system. On the other hand, our environment is full of waste and unused energy such as that coming from the sun or mechanical vibrations. As a result, commercial energy harvesters are increasingly available to power autonomous sensors. This work presents and analyses commercial energy harvesters currently available. First, environmental energy sources are classified and described. Then, energy harvesting principles are described and some guidelines are given to calculate the maximum power consumption allowed and the energy storage capacity required for the autonomous sensor. Finally, commercial energy harvesters are evaluated to determine their capability to power a commercial autonomous sensor in some given circumstances.
\end{abstract}

Keywords - Commercial energy harvesters, energy harvesting, harvesting principles, wireless sensor nodes, autonomous sensors.

\section{INTRODUCTION}

Autonomous sensors are wireless measurement systems used in multiple applications from healthcare to environmental monitoring. Current autonomous sensors are mainly powered by primary batteries, so that for systems intended to work for several years they need to be low power and remain inactive most of the time. Even so, primary batteries may become the largest and most expensive of their constituent part. On the other hand, measuring the state of charge of a battery is difficult and has no optimal solution, so that system reliability asks for periodical battery replacement, as in fire alarm sensors and healthcare applications. Battery replacement can also be expensive in cases such as remote environmental monitoring, or unpractical, as in applications with sensors embedded in building materials or structures. For sensor networks with hundreds or thousands of nodes, the savings in wiring may not pay for the workload of battery replacement. Hence, "real" autonomous sensors ask for a long-term power source, such as that available from energy harvesting.

This paper first describes the environmental energy sources available to power autonomous sensors. Then, the general building blocks of an energy harvester are presented and the design guidelines that such a system must follow are given. Finally, commercially available energy harvesters are described and their capability to power one specific commercial autonomous sensor is analyzed.

\section{ENVIRONMENTAL ENERGY SOURCES}

Our environment is full of waste and unused energy. Solar and wind energy have been used for years and the last decade has seen a lot of research effort to use any kind of energy to supply autonomous sensors. Thomas et al. [1] extensively describe many energy sources to power small-scale unmanned systems. Starting from their classification, we group harvested energy intended for autonomous sensors into five types: radiant, mechanical, thermal, magnetic, and biochemical (Fig. 1). Typical power densities are given in [2, 3]. Some of these energy types can also be deliberately beamed.

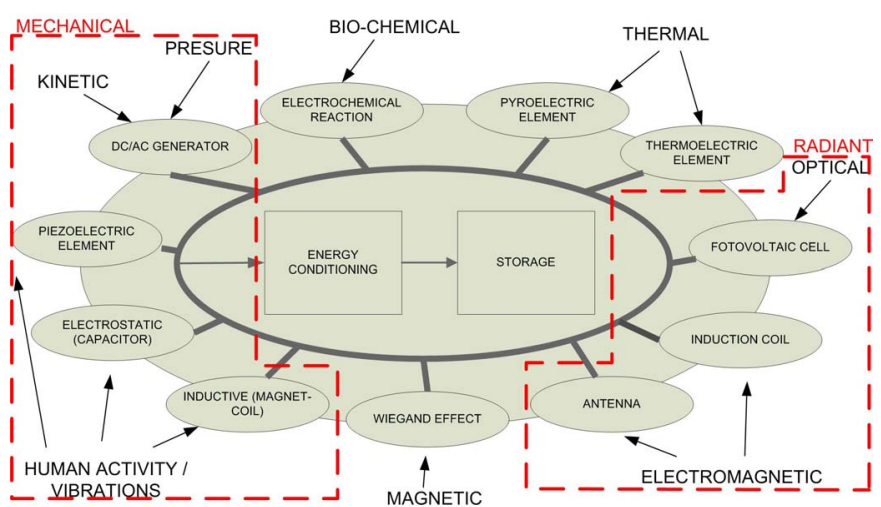

Fig. 1. Energy sources and respective transducers to power autonomous sensors. Adapted from [1] with additional power sources.

- Radiant energy is the energy radiated as electromagnetic waves and is pervasive. Optical energy $[4,5]$ includes the electromagnetic spectrum form infrared to ultraviolet light. Indoor power density typically ranges from $100 \mu \mathrm{W} / \mathrm{cm}^{2}$ to $1000 \mu \mathrm{W} / \mathrm{cm}^{2}$, and outdoors can be up to $100 \mathrm{~mW} / \mathrm{cm}^{2}$. Solar cells can be monocristalline, polycrystalline, amorphous silicon or thin film, and their efficiency ranges from $30 \%$ (monocristalline cells) to $5 \%$ (thin film cells) [1]. Electric and magnetic fields emanate from power lines. Radiofrequency (RF) signals are deliberately radiated by broadcasting stations and cellular phone antennas, so they are also pervasive. However, the power available from them is in the nanowatt range. Efficiency depends on the input power, and is $20 \%$ maximal for microwatt-level inputs [6]. Radioactive materials contain extremely high energy densities, and their half-life can be from fractions of a second 
to millions of years. Their energy can be converted by piezoelectric or betavoltaic elements, which determine their efficiency [7].

- Mechanical energy harvesting is based on kinetic energy. This energy can be coupled by one of the mechanic-electric conversion principles [8]: electrostatic, piezoelectric and inductive (based on Faraday's law). Typical efficiencies are respectively: $0.32 \%$ [9]; $0.5 \%$ (PVDF) to $20 \%$ (PZT) [10]; and $6 \%$ [9]. Some sources of kinetic energy are: liquid or gas flow energy, vibrations [5], human activity and pressure variations [3] such as acoustic noise and atmospheric pressure.

- Thermal energy can be converted to electrical energy by thermoelectric or pyroelectric transducers. The thermoelectric principle relies on temperature variations in space, and the pyroelectric effect relies on temperature variations with time. Pyroelectric transducers yield very low efficiencies [11]. For thermoelectric transducers, the maximal efficiency is given by the Carnot efficiency, $\eta=\left(T_{\mathrm{H}}-T_{\mathrm{C}}\right) / T_{\mathrm{H}}$, where $T_{\mathrm{H}}$ and $T_{\mathrm{C}}$ are respectively the hot and cold temperatures in Kelvin [3].

- Magnetic energy [1] is available near current-carrying conductors, magnets, and electric rotating machinery. Faraday's law is used to convert this energy using a coil. The Wiegand effect [12] can also produce electrical energy from a varying magnetic field, but very low efficiencies are expected.

- Biochemical energy [13] can be extracted by fuel cells, yet small scale efficiencies of only $0.5 \%$ have been achieved up to now.

\section{ENERGY HARVESTING PRINCIPLES}

Fig. 2 shows the block diagram of an autonomous sensor that harvests all of its energy from the environment. The load normally consists of sensors, signal conditioners, processor and RF transceiver. The blocks inside the dashed red box constitute the energy harvester, which replaces the primary battery. The transducer turns environmental energy into electrical energy, with a given efficiency. Energy storage is needed to provide a constant power flow to the load from a variable environmental source. The energy conditioning block is used to properly charge the storage unit. The power conditioning block provides the appropriate power supply to the load.

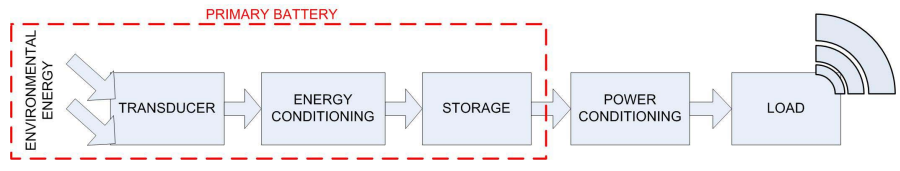

Fig. 2. Block diagram of an autonomous sensor. The blocks inside the dashed red box form the energy harvester subsystem.

For a perpetual operation it must be

$$
\overline{P_{\mathrm{g}}} \geq \overline{P_{\mathrm{c}}}
$$

where $\bar{P}_{\mathrm{g}}$ and $\bar{P}_{\mathrm{c}}$ are respectively the generated and the consumed mean power. Autonomous sensors often have a very low duty cycle, $D$, moderate power consumption in active mode, $P_{\text {active }}$ (tens or hundreds of milliwatt), and very low power consumption while idle (sleep mode), $P_{\text {sleep }}$ (units or tens of microwatts). Then, the consumed mean power can be approximated as

$$
\overline{P_{\mathrm{c}}}=P_{\text {sleep }}+D P_{\text {active }}
$$

From (1) and (2) the maximal duty cycle is

$$
D_{\mathrm{MAX}}=\frac{\overline{P_{\mathrm{g}}}-P_{\text {sleep }}}{P_{\text {active }}}
$$

Due to the variability of environmental energy sources, a storage unit is needed. This reservoir must power the load whenever $P_{\mathrm{g}}<P_{\mathrm{c}}$. For any arbitrary long time period $T$, a long-term storage ( $\left.E_{\text {storage }}\right)$ unit must fulfill the condition

$$
E_{\text {storage }} \geq \max \left\{\int_{T}\left(P_{\mathrm{c}}-P_{\mathrm{g}}\right) d t\right\}
$$

Even if $P_{\mathrm{g}}$ is constant, for example power coming from permanent indoor lights, a short-term storage is needed to withstand the impulsive-type consumption profile of an autonomous sensor. Fig. 3 illustrates this situation when $P_{\text {active }}>P_{\mathrm{g}}$.

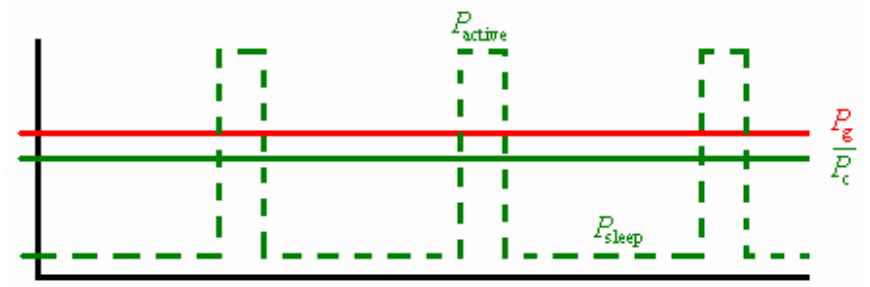

Fig. 3. Power consumption when $\mathrm{P}_{\text {active }}>\mathrm{P}_{\mathrm{g}}$.

Supercapacitors and rechargeable batteries can be used as energy storage units. Sometimes they are used simultaneously because of their complementary characteristics. Reference [14] provides a comparison with special focus on autonomous sensors.

Table 1 summarizes some power characteristics of commercial transceivers used in autonomous sensors. Even though the load in Fig. 2 includes other subsystems, these can take far less power than the transceiver, provided they are judiciously designed. Therefore, the overall energy consumption of the autonomous sensor is mainly that of the transceiver. 
Table 1. Power specifications of transceivers in some commercial sensor nodes.

\begin{tabular}{|c|c|c|c|c|}
\hline \multicolumn{2}{|c|}{ Wireless Sensor Node } & $V_{\text {cd }} / \mathrm{V}$ & $\begin{array}{c}P_{\text {active }} \\
\mathrm{mW}\end{array}$ & $\begin{array}{c}P_{\text {Sleep }} / \\
\mu \mathrm{W}\end{array}$ \\
\hline CrossBow & $\begin{array}{c}\text { MicaZ } \\
\text { OEM }\end{array}$ & $2.1-3.6$ & 55.6 & 3 \\
\cline { 2 - 5 } Mica2Dot & $2.7-3.3$ & 55.5 & $<3$ \\
\hline Dust Networks Nodes & $2.7-3.3$ & 63 & 30 \\
\hline Ember, EM 250 & $2.1-3.6$ & 106.5 & 3 \\
\hline MicroStrain 2400 Series & $\begin{array}{c}3.7(600 \mathrm{mAh} \\
\text { internal Li-Ion } \\
\text { battery) }\end{array}$ & 75 & 1500 \\
\hline
\end{tabular}

\section{COMMERCIAL ENERGY HARVESTERS}

Table 2 lists some commercial energy harvesters based on different energy conversion principles and their most relevant characteristics. Most of them have similar dimensions (below $10 \mathrm{~cm}$ ) to the autonomous sensors they must power. $D_{\mathrm{MAX}}$ is calculated from (3) by assuming a constant $P_{\mathrm{g}}$ based on data provided by manufacturers. The Ember transceiver in Table 1 has been chosen as the reference load for $P_{\text {active }}$ and $P_{\text {sleep }}$ in (3). Energy harvesters that do not include any energy reservoir need at least a short-term storage unit whenever $P_{\text {active }}>P_{\mathrm{g}}$.

\section{A. Radiant energy harvesters}

A.1 Electromagnetic energy harvesters. Powercast offers transmitter (WPT Series) and receiver (WPR Series) devices that can respectively beam and harvest RF energy. Maximal transmitted power is limited to $1 \mathrm{~W}$ for compliance with $\mathrm{RF}$ safety standards. The receiver has a conversion efficiency of up to $70 \%$. Voltage outputs from $1.2 \mathrm{~V}$ to $6 \mathrm{~V}$ are available. If we assume $1 \mathrm{~W}$ of radiated power, free space propagation conditions, $1 \mathrm{~m}$ between transmitter and receiver, and unity gain antennas, the harvested power ranges from $98.9 \mu \mathrm{W}$ (at $f$ $=2.4 \mathrm{GHz}$ ) to $694.6 \mu \mathrm{W}$ (at $f=905.8 \mathrm{MHz}$ ) [15]. If the receiver has an efficiency of $70 \% D_{\mathrm{MAX}}$ ranges from $0.06 \%$ (at $f=2.4 \mathrm{GHz}$ ) to $0.45 \%$ (at $f=905.8 \mathrm{MHz}$ ).

Commercial devices based on inductive links are mainly intended for consumer electronics [16], hence unsuitable for unattended autonomous systems. There is one patent on parasitic RF harvesting [17] but to the best knowledge of the authors no commercial product is available yet.

Passive RFID tags [18] are electromagnetic energy harvesters to some extent since they collect energy beamed by a reader, and use it to power their electronics and to answer with a unique identification. Tags with sensing capability are increasingly available [19].

A.2 Optical energy harvesters. Solar cells provide the energy transducer but lack functions such as energy conditioning or storage. So, only solar battery chargers and systems with these additional functions are considered here.

\footnotetext{
* Calculated from the average current consumed in the receiving and transmitting modes, and $V_{\mathrm{cc}}=3 \mathrm{~V}$.
}

- STM 100 (EnOcean): This is an autonomous system by itself that accepts signals coming from output voltage sensors. The solar cell used is divided into two sections: $70 \%$ of the area is used to charge a $0.1 \mathrm{~F}$ supercapacitor (main energy storage) and the remaining $30 \%$ area is used to enable a fast start when the supercapacitor is depleted. This partition and the use of a Schottky diode for current blocking are energy conditioning functions. Hence, this product implements the three blocks of an energy harvester (Fig. 2). If the harvester were separated from the system, $D_{\mathrm{MAX}}$ would be $0.05 \% @ 1000$ lx. A much higher duty cycle is expected with direct sunlight. A fully charged capacitor provides 133 min backup power for $D=0.05 \%$, which is not enough to last one dark night.

- The Solio ${ }^{\circledR}$ Universal Hybrid Solar Charger has been designed to charge iPod ${ }^{\circledR}$ or cell phones at outdoor irradiances. An internal rechargeable battery $(3.6 \mathrm{~V}$ and $1600 \mathrm{mAh}$ ) is provided for extra energy storage. It can also be charged from a wall adapter. This charger includes the first three blocks in Fig. 2. Some kind of power management is also implemented to provide voltage outputs between $4 \mathrm{~V}$ and $12 \mathrm{~V}$; therefore some additional $\mathrm{dc} / \mathrm{dc}$ converter should be added to match the voltage range of an Ember transceiver. With an outdoor irradiance of $1000 \mathrm{~W} / \mathrm{m}^{2}$ the current generated is $165 \mathrm{~mA}$, hence higher than the current sunk by the Ember transceiver in active mode; this means that we can design $D=100 \%$. A fully charged battery provides $45 \mathrm{~h}$ of backup power for $D=100 \%$. A discontinuous operation is expected at indoor irradiance conditions. Other systems available for consumer electronics are the Voltaic Solar Bags [20] (2200 $\mathrm{mAh}$ rechargeable battery).

\section{B. Mechanical energy harvesters}

There are no electrostatic-based commercial energy harvesters, but piezoelectric and inductive harvesters are common to harvest vibration energy.

- The PMG7 (Perpetuum) is based on a magnet and coil arrangement that transforms the kinetic energy of vibration into a low power electrical signal (Faraday's law). It is designed to resonate at mains frequency $(50 \mathrm{~Hz}$ or $60 \mathrm{~Hz})$. A $3.3 \mathrm{~V}$ regulated output is provided, but otherwise there is no energy storage. With a continuously vibrating source, $D_{\mathrm{MAX}}$ ranges from $0.09 \%$ to $0.37 \%$ at $25 \mathrm{mg}$, and from $1.87 \%$ to $4.69 \%$ at $100 \mathrm{mg}$.

- The FS Energy harvester (Ferro Solutions) also relies on Faraday's law. Its natural frequency is $21 \mathrm{~Hz}$. A $3.3 \mathrm{~V}$ regulated output (by default) is provided. A supercapacitor is used to store energy but no data about its value is available. $D_{\text {MAX }}$ is $0.37 \%$ for a source vibrating at $20 \mathrm{mg}$, and $8.7 \%$ at $100 \mathrm{mg}$.

- APA400M-MD (Cedrat) is a piezoelectric harvester based on a proof mass configuration. Its natural frequency is $110 \mathrm{~Hz}$. This harvester includes an ac/dc rectification stage and a fly-back de/dc converter. $D_{\mathrm{MAX}}$ is $37.55 \%$ at $35 \mu \mathrm{m}$ peak-to-peak of harvested vibration amplitude. 
- Volture (MIDE) uses the piezoelectric principle. Natural frequencies from $50 \mathrm{~Hz}$ to $150 \mathrm{~Hz}$ are available. $D_{\mathrm{MAX}}$ is $0.04 \%$ at $240 \mathrm{mg}$.

Kinetron provides only energy transducers that transfer mechanical energy to an ac voltage. ECO 100 (EnOcean) harvests energy from linear motion to power its own transceiver but it cannot power the Ember transceiver. The harvester provides a burst of power each time it is externally actuated. Model 101 (Etesian Technologies) powers an internal wind meter with the same wind source. No information about the power generated is provided by the manufacturer.

\section{Thermal energy harvesters}

Commercial thermal transducers based on the thermoelectric (Seebeck) effect consist of several thermocouples electrically connected in series and thermally placed in parallel. Voltage depends on temperature difference, so low voltages are expected for body-level temperature differences. However, no energy conditioning and storage is implemented. Some manufactures are: Thermo Life; Micropelt; Thermoelectrics.com; Peltron GmbH; TE Technology Inc.; HiZ Technology; Kryotherm, and Tellurex. Devices from the last three manufacturers can accept continuous operation of the Ember transceiver if there is a temperature difference of $80^{\circ} \mathrm{C}$.

\section{Energy harvesting modules}

Advanced Linear Devices has recently announced the EH300 series EPAD ${ }^{\circledR}$ energy harvesting ${ }^{\mathrm{TM}}$ modules. They include the energy conditioning and storage blocks in Fig. 2. The manufacturer claims that these modules can extract energy from any environmental energy source (ac or dc signals ranging from $0 \mathrm{~V}$ to $\pm 500 \mathrm{~V}$ and from $200 \mathrm{nA}$ to $400 \mathrm{~mA}$ ). The storage unit is provided by a capacitor bank and then the output voltage linearly decreases for a constant output current. The output of the module is only activated when the output voltage lies within two voltage thresholds. Two different models offer respectively outputs from $3.6 \mathrm{~V}$ to $1.8 \mathrm{~V}(\mathrm{EH} 300)$ and from $5.2 \mathrm{~V}$ to $3.1 \mathrm{~V}$ (EH301), thus suitable to power most autonomous sensors. For each model, two energy storage options are possible. The manufacturer provides data of available energy and active time outputs for a rated current. From these data, the calculated capacitances are $950 \mu \mathrm{F}$ and $6.25 \mathrm{mF}$. The EH300 model can power the Ember transceiver and the option with the highest storage capacity can power the transceiver for $264 \mathrm{~ms}$, when fully charged. Then, only short-term storage is provided.
Table 2. Commercial energy harvesters.

\begin{tabular}{|c|c|c|c|}
\hline Product & $\begin{array}{c}V_{\text {out }} / \\
\mathrm{V}\end{array}$ & Output Power & $\begin{array}{c}\text { Dimensions / } \\
\mathrm{mm}\end{array}$ \\
\hline $\begin{array}{l}\text { WPT Series + WPR } \\
\text { Series; Powercast }\end{array}$ & $\begin{array}{c}1.2- \\
6\end{array}$ & $\begin{array}{c}160^{\dagger} \mu \mathrm{A} @ 905.8 \mathrm{MHz} \\
23^{\dagger} \mu \mathrm{A} @ 2.4 \mathrm{GHz}\end{array}$ & $\begin{array}{c}5.08 \times 2.54 \\
\text { for WPT } \\
2.54 \times 1.27 \\
\text { for WPR }\end{array}$ \\
\hline $\begin{array}{l}\text { STM } 100 \text { / STM 250; } \\
\text { EnOcean }\end{array}$ & $3-4$ & $22^{\ddagger} \mu \mathrm{A} @ 10001 \mathrm{x}$ & $21 \times 40 \times 12$ \\
\hline $\begin{array}{c}\text { Solio }{ }^{\circledR} \text { Solar } \\
\text { Charger; Solio }\end{array}$ & $\begin{array}{l}4- \\
12 \\
\end{array}$ & $165 \mathrm{~mA} @ 1000 \mathrm{~W} / \mathrm{m}^{2}$ & $\begin{array}{c}119.4 \times 33 \times \\
63.5\end{array}$ \\
\hline $\begin{array}{l}\text { PMG7-50/60; } \\
\text { Perpetuum }\end{array}$ & 3.3 & $\begin{array}{c}0.1 \mathrm{~mW}-0.4 \mathrm{~mW} \\
25 \mathrm{mg} / 2 \mathrm{~mW}-5 \mathrm{~mW} \\
@ 100 \mathrm{mg}\end{array}$ & $26.5 \varnothing \times 23$ \\
\hline $\begin{array}{c}\text { FS Energy } \\
\text { Harvesters; } \\
\text { FerroSolutions } \\
\end{array}$ & 3.3 & $\begin{array}{l}0.4 \mathrm{~mW} @ 20 \mathrm{mg} / \\
9.3 \mathrm{~mW} @ 100 \mathrm{mg}\end{array}$ & $45.7 \varnothing \times 45.7$ \\
\hline $\begin{array}{l}\text { APA400M-MD; } \\
\text { Cedrat }\end{array}$ & $\mathrm{N} / \mathrm{A}$ & $\begin{array}{c}40 \mathrm{~mW} 33 \mu \mathrm{m}, 110 \\
\mathrm{~Hz}\end{array}$ & $50 \times 32 \times 22$ \\
\hline Volture; MIDE & N/A & $\begin{array}{c}43 \mu \mathrm{W} @ 240 \mathrm{mg} 120 \\
\mathrm{~Hz}\end{array}$ & $\begin{array}{c}92.7 \times 43.8 \times \\
9.9 \\
\end{array}$ \\
\hline $\begin{array}{c}\text { HZ-2; HiZ } \\
\text { Technology }\end{array}$ & 3.3 & $\begin{array}{c}300 \mathrm{~mW} @ \Delta \theta=(100 \\
\left.{ }^{\circ} \mathrm{C}-20{ }^{\circ} \mathrm{C}\right) \text { load } \\
\text { matched }\end{array}$ & $29 \times 29 \times 5.1$ \\
\hline $\begin{array}{l}\text { TGM-127-1.0-1.3; } \\
\text { Kryotherm }^{\S}\end{array}$ & 2.6 & $\begin{array}{c}485 \mathrm{~mW} @ \Delta \theta=(100 \\
\left.{ }^{\circ} \mathrm{C}-20^{\circ} \mathrm{C}\right) \text { load } \\
\text { matched }\end{array}$ & $30 \times 30 \times 3.6$ \\
\hline $\begin{array}{l}\text { CZ1-1.0-127-1.27 } \\
\text { HT; Tellurex }\end{array}$ & 3.5 & $\begin{array}{c}500 \mathrm{~mW} @ \Delta \theta=(100 \\
\left.{ }^{\circ} \mathrm{C}-20{ }^{\circ} \mathrm{C}\right) \text { load } \\
\text { matched }\end{array}$ & $34 \times 31 \times 3.3$ \\
\hline
\end{tabular}

\section{V.CONCLUSION}

Autonomous sensors are mainly powered by primary batteries. However, batteries need to be replaced and can become the largest and most expensive part of the system. Energy harvesting is an alternative to primary batteries.

Energy sources to power autonomous sensors have been classified and described, and the building blocks of an energy transducer have been presented. A complete energy harvester must include a transducer, an energy conditioning block and an energy storage unit. We have given design guidelines to determine the maximal duty cycle and the required storage capacity of the autonomous sensor. Long-term storage accounts for the variability of the environmental energy source and short-term storage provides the required energy when the autonomous sensor is in the active mode.

Based on this, commercial energy harvesters currently available have been analyzed to determine when they can power a commercial autonomous sensor. Solar energy harvesters offer a large variety of transducers, but only a few solar battery chargers are available that are not very suitable to power autonomous sensors. Other solutions include the complete autonomous sensor and then the energy harvester subsystem cannot be separately used. Thermal harvesters

\footnotetext{
${ }^{\dagger}$ Assuming an omni-directional transmitted power of $1 \mathrm{~W}$, free space propagation conditions, $1 \mathrm{~m}$ of distance between the transmitter and the receiver, and an efficiency of $70 \%$ at the receiver.

Measured

${ }^{\S}$ Values from [1]
} 
include only the energy transducer, then the energy conditioning and storage blocks must be externally added. There is only one commercial RF harvester available, which is based on beaming RF energy; antennas (transducers) must be added. Vibration harvesting seems the most active area and an everyday increasing number of devices are available. Vibration frequencies range from $20 \mathrm{~Hz}$ to $150 \mathrm{~Hz}$. Some vibration harvesters are complete energy harvesters but others lack storage or even ac/dc conversion. One device that includes the energy conditioning and storage blocks for any kind of energy transducer has also been marketed. The storage unit is only intended for short-term supply.

To sum up, multiple options to power autonomous sensors from the environmental energy are available. The transducer and long-term storage unit must be tailored to the specific application, so it is difficult that a single product meets all the application conditions. Some energy harvesters are part of a whole autonomous sensor, so they can be specifically tailored to the system needs. Others are available as standalone systems and can include some or all the parts of an energy harvester. In this case, their usefulness depends on their adaptability to a high number of applications or their use in highly-demanded applications. Vibration harvesters belong to this second group. Finally, products that only implement an energy conditioning block for any transducer combined with a short-term storage unit can also find their place on the market.

\section{AKNOWLEDGEMENT}

This work has been funded in part by the Spanish Ministry of Education and Science under contract TEC2004-05520 and by the European Regional Development Fund. Maria Teresa Penella has a grant from the Ministry of Education and Science of Spain on the FPU program (AP2005-2508). The authors also appreciate the ideas and support offered by Prof. R. Pallàs-Areny.

\section{REFERENCES}

[1] J. P. Thomas, M. A. Qidwai, and J. C. Kellogg, "Energy scavenging for small-scale unmanned systems," Journal of Power Sources, vol. 159, pp. 1494-1509, 2006.
[2] O. Kanoun and H.-R. Tränkler, "Energy-Management for Power Aware Portable Sensor Systems," in Proc. IMTC 2006 - Instrumentation and Measurement Technology Conference, 2006, pp. 1673 - 1678.

[3] S. Roundy, J. M. Rabaey, and P. K. Wright, Energy Scavenging for Wireless Sensor Networks, with Special Focus on Vibrations, 1 st ed. Norwell, Massachusetts: Kluiwer Academic Publishers, 2004.

[4] J. F. Randall, Designing Indoor Solar Products. Photovoltaic Technologies for AES, 1 ed. West Sussex: John Wiley \& sons, 2005.

[5] S. Roundy, D. Steingart, L. Frechette, P. Wright, and J. Rabaey, "Power sources for wireless sensor networks," in Proc. 1st European Workshop on Wireless Sensor Networks (EWSN'04), 2004, pp. 1-17.

[6] J. A. Hagerty, F. B. Helmbrecht, W. H. McCalpin, R. Zane, and Z. B. Popovic, "Recycling ambient microwave energy with broad-band rectenna arrays," IEEE Trans. on Microwave Theory and Techniques, vol. 52, pp. 1014-1024, 2004.

[7] N. Mokhoff (2006, Sep.). IEDM feels the power. Online EETimes Europe [Online]. Available: http://www.eetimes.eu/193000825

[8] S. P. Beeby, M. J. Tudor, and N. M. White, "Energy harvesting vibration sources for microsystems applications," Measurement Science and Technology, vol. 17, pp. R175, 2006.

[9] P. D. Mitcheson, T. C. Green, E. M. Yeatman, and A. S. Holmes, "Architectures for vibration-driven micropower generators," Journal of Microelectromechanical Systems, vol. 13, pp. 429-440, 2004.

[10] N. S. Shenck and J. A. Paradiso, "Energy scavenging with shoemounted piezoelectrics," IEEE Micro, vol. 21, pp. 30-42, 2001.

[11] A. Cuadras, M. Gasulla, A. Ghisla, and V. Ferrari, "Energy harvesting from PZT pyroelectric cells," in Proc. IMTC 2006 - Instrumentation and Measurement Technology Conference, 2006, pp. 1668 - 1672.

[12] D. J. Dlugos, D. Small, and D. A. Siefer, "Wiegand effect energy generators", WO0017997, Mar. 30, 2000.

[13] P. Woias, Y. Manoli, T. Nann, and F. V. Stetten, "Energy harvesting for autonomous microsystems," Mst News, pp. 42 - 45, 2005.

[14] V. Raghunathan, A. Kansal, J. Hsu, J. Friedman, and M. Srivastava, "Design considerations for solar energy harvesting wireless embedded systems," in Proc. Fourth International Symposium on Information Processing in Sensor Networks, 2005, pp. 457-462.

[15] J.-P. Curty, M. Declercq, C. Dehollain, and N. Joehl, "Wireless power transmission," in Design and Optimization of Passive UHF RFID Systems, 1st ed., New York: Springer Science+Business Media, 2007, pp. 3-17.

[16] Splashpower, Splashpower- wireless power for your mobile devices., Splashpower, Cambridge, UK [Online] Available: http://www.splashpower.com/

[17] K. Moshe, "EMI energy harvester", US Patent 2006170217, Aug. 3, 2006.

[18] Texas Instruments, RFID / EPC Technology Solutions., Texas Instruments, Dallas, TX [Online] Available: http://www.ti.com/rfid/default.htm

[19] MicroStrain, MicroStrain: Orientation Sensors - Wireless Sensors, MicroStrain, Williston, VT [Online] Available: http://www.microstrain.com/

[20] Voltaic Systems, Voltaic Backpack, Solar Backpack, Solar Bag, Voltaic Systems, Coquitlam, Canada [Online] Available: http://www.voltaicsystems.com/ 